Retrospective Review

\title{
Multivariable Analysis of the Relationship Between Pain Referral Patterns and the Source of Chronic Low Back Pain
}

Ben L. Laplante, DO ${ }^{1}$, Jessica M. Ketchum, $\mathrm{PhD}^{2}$, Thomas R. Saullo, MD², and Michael J. DePalma, MD ${ }^{1}$

From: ${ }^{1}$ Virginia iSpine Physicians, PC, Richmond, VA and Virginia Spine Research Institute, Richmond, VA; ${ }^{2}$ Virginia Commonwealth University, Richmond, VA; ${ }^{3}$ Spine and Scoliosis Specialists, Greensboro, NC;

Dr. Laplante, is an Interventional Spine Fellow at Virginia iSpine Physicians; and a Clinical Research

Fellow with Virginia Spine Research Institute, Inc, Richmond, VA. Dr. Ketchum is Assistant Professor of the Department of Biostatistics, Virginia Commonwealth University, Richmond, VA. Dr. Saullo is with Spine and Scoliosis Specialists, Greensboro, NC. Dr. DePalma is President, Medical Director, Interventional Spine Care Fellowship

Virginia iSpine Physicians, PC; and President, Director of Research for Virginia Spine Research Institute, Inc, Richmond, VA.

Address correspondence: Michael J. DePalma, MD

President, Medical Director Director, Interventional Spine Care Fellowship

Virginia iSpine Physicians, PC President, Chairman, Director of Research

Virginia Spine Research Institute, Inc 9020 Stony Point Pkwy, Ste 140 Richmond, VA 23235

Email: depalmamj8@yahoo.com

Disclaimer: Dr. DePalma is a coinvestigator on clinical trials for Spinal Restoration, Stryker Biotech, Crosstrees, and ATRM. Conflict of interest: None.

Manuscript received: 10/11/2011 Revised manuscript received: $11 / 30 / 2011$

Accepted for publication: 12/27/2011

Free full manuscript: www.painphysicianjournal.com
Background: Discogenic, facet joint, and sacroiliac joint mediated axial low back pain may be associated with overlapping pain referral patterns into the lower limb. Differences between pain referral patterns for these three structures have not been systematically investigated.

Objective: To examine the individual and combined relationship of age, hip/girdle pain, leg pain, and thigh pain and the source of internal disc disruption (IDD), facet joint pain (FJP), or sacroiliac joint pain (SIJP) in consecutive chronic low back pain (CLBP) patients.

Design: Retrospective chart review.

Setting: Community based interventional spine practice.

Patients: 378 cases from 358 consecutive patients were reviewed and 157 independent cases from 153 patients who underwent definitive diagnostic injections were analyzed.

Methods: Charts of consecutive low back pain patients who underwent definitive diagnostic spinal procedures were retrospectively reviewed. Patients underwent provocation lumbar discography, dual diagnostic medial branch blocks, or intra-articular diagnostic sacroiliac joint injections based on clinical presentation. Some subjects underwent multiple diagnostic injections until the source of their chronic low back pain (CLBP) was identified.

Main Outcome Measurements: Based on the results of diagnostic injections, subjects were classified as having IDD, FJP, SIJP, or other. The mean age/standard deviation and the count/percentage of patients reporting hip girdle pain, leg pain, or thigh pain were estimated for each diagnostic group and compared statistically among the IDD, FJP, SIJP, and other source groups. Next, the 4 predictor variables were simultaneously modeled with a single multinomial logistic regression model to explore the adjusted relationship between the predictors and the source of CLBP.

Results: The mean age was significantly different among the source groups. IDD cases were significantly younger than FJP, SIJP, and other source groups and FJP cases were significantly younger than other sources. The age by thigh pain interaction effect was statistically significant $(P=0.021)$, indicating that the effect of age on the source of CLBP depends on thigh pain, and similarly, that the effect of thigh pain on the source of CLBP depends on age.

Limitations: Retrospective study design.

Conclusions: The presence or absence of thigh pain possesses a significant correlation on the source of CLBP for varying ages, whereas the presence of hip/girdle pain or leg pain did not significantly discriminate among IDD, FJP, or SIJP as the etiology of CLBP. Younger age was predictive of IDD regardless of the presence or absence of thigh pain.

Key words: low back pain, intervertebral disc, zygapophyseal joint, sacroiliac joint, pain referral patterns

Pain Physician 2012; 15:171-178 
D espite the inherent challenge in elucidating the specific etiology of chronic low back pain (CLBP), diagnostic procedures can reveal its source in $90 \%$ of patients (1). Prevalence rates for internal disc disruption (IDD), facet joint pain, (FJP) and sacroiliac joint pain (SIJP) have been estimated to be $42 \%, 31 \%$, and $18 \%$, respectively (2). The precise location of a patient's low back pain can predict its source (3). Pain emanating from the aforementioned structures may concomitantly refer pain outside of the axial lumbar region into the lower limb (4). Recognition of the pain referral patterns characteristic for IDD, FJP, and SIJP may sharpen the evaluating clinician's diagnostic acumen in formulating an efficient and costeffective diagnostic investigation and treatment plan.

IDD, FJP, and SIJP have been observed to refer pain to the lower lumbar spine, posterior superior iliac spine, buttock, trochanteric region, groin, ischial tuberosity, thigh, leg, ankle, and foot (5-28). Despite common referral patterns, differences among these referral patterns from these 3 structural sources have not been systematically investigated. The purpose of the present study was to examine the individual and combined relationship of age, hip/girdle pain, leg pain, and thigh pain and the source of IDD, FJP, or SIJP in consecutive CLBP patients presenting to a community-based, multidisciplinary, academic spine center.

\section{Methods}

\section{Participants}

After obtaining Institutional Review Board approval, 378 consecutive cases from 358 LBP patient's charts were reviewed. The cases were from patients suffering from LBP recalcitrant to spine focused physical therapy, oral analgesics, and oral anti-inflammatory medications whose LBP was incapacitating and thus interfering with daily activities. All patients presented to a communitybased, multi-disciplinary, academic spine center from November 2007 through December 2008. Patients were referred to the spine center from community and university spine surgeons (neurosurgery and orthopedics), physiatrists, non-spine surgeons, primary care physicians, rheumatologists, endocrinologists, neurologists, and occupational health physicians.

Eighteen patients presented with more than one case during the period the charts were reviewed; 16 patients with two cases and 2 patients with 3 cases (total of 38 cases). Seven of the eighteen patients presented with multiple cases at the same point in time
( 6 with two cases, and 1 with three cases), and the remaining 11 presented at different points in time (10 with two cases and 1 with three). The seven cases with multiple cases at the same point in time were excluded because these sources could not be considered independent events. Of the remaining 363 cases from 351 patients, 157 cases went on to have diagnostic procedures and 206 did not because their LBP improved and they did not require diagnostic injections to institute definitive care. These patients were excluded from the analysis. Thus, the sample used for analysis consists of 157 cases from 153 patients who had definitive diagnostic testing to identify the source of their LBP.

\section{Measures}

To determine the source of LBP, each patient underwent provocation lumbar discography (PLD), dual diagnostic facet joint blocks (FJB) with local comparative anesthetics, or intra-articular diagnostic SIJ injections (SIJB). Some patients underwent multiple diagnostic procedures until the source of their LBP was identified. If the initial diagnostic procedure was negative, the next most likely structure in the diagnostic algorithm was interrogated. For ethical reasons, once a source of the subject's LBP was identified, subsequent diagnostic procedures were not performed.

Patients reporting paravertebral LBP without midline LBP $(14,23)$ which was exacerbated by standing and/or walking (24) and who demonstrated $\leq 2$ positive SIJ provocative maneuvers (31) and/or a lack centralization during McKenzie evaluation (32) typically underwent FJB first, followed by SIJB and then PLD if the preceding diagnostic procedure was negative. The side and joint level selected by pain referral pattern $(21,33)$ were investigated by first moving from most likely to less likely facet joint (FJ) level. Patients reporting paravertebral $\operatorname{LBP}$ without midline $\operatorname{LBP}(6,7,13,14,26,34,35)$ and 3 positive out of 5 SIJ provocative maneuvers $(31,36)$ without centralization during McKenzie evaluation (32) underwent SIJB followed by FJBs and then PLD unless the initial diagnostic blocks were positive. Patients reporting midline LBP with or without paravertebral LBP, centralization during McKenzie evaluation (32), and/or LBP during SHR (37) underwent PLD initially followed by FJB or SIJB if discography was negative.

Positive discography was defined as concordant/ partial concordant LBP $(>6 / 10)$ at low pressure $(<50$ psi over opening pressure) due to $\geq$ Grade III annular tears $(27,38,39)$. Diagnostic blockade of FJ or SIJ 
was deemed positive if the patient's index pain was relieved by $\geq 75 \%$ after injection of each anesthetic $(6,7,13,14,26,34,35)$.

Based on the results of the diagnostic procedures, subjects were classified as having IDD, FJP, SIJP, or Other sources of LBP (fusion hardware mediated soft tissue pain, Baastrup's Disease, or vertebral or sacral insufficiency fractures). The source of LBP was the primary outcome variable of interest in this study. The predictor variables considered for this analysis include age at initial presentation (in years), hip girdle pain (present/absent), leg pain (present/absent), and thigh pain (present/absent).

\section{Statistical Analyses}

Initially, the prevalence of each source of CLBP in this population was estimated by computing the proportion of patients with each diagnostic source out of all diagnosed patients. The mean age/standard deviation (SD) and the count/percentage of patients reporting hip girdle pain, leg pain, or thigh pain were estimated for each diagnostic group and compared statistically between the IDD, FJP, SIJP, and Other source groups using ANOVA and chi-square tests.

Next, the bivariate relationship between each of the predictor variables and the probability of the sources of CLBP (IDD, FJP, SIJP, or other) was estimated with a multinomial logistic regression analysis assuming a generalized logit link function. The four predictor variables were then simultaneously modeled with a single multinomial logistic regression model to explore the adjusted relationship between the predictors and the source of CLBP. Pairwise interaction effects among the predictors variables were tested to determine if the effect of one predictor on the source of CLBP depends on (or is modi- fied by) another predictor. Odds ratios were used to describe the unadjusted and adjusted relationship between the predictor variables and the source of CLBP. SAS v.9.2 (Copyright @ 2002-2008 by SAS Institute Inc., Cary, NC, USA) was used for all data analyses and Microsoft $®$ Office Excel $® 2007$ was used for all graphics.

\section{Results}

Cases of LBP were primarily female $(67 \%)$, presented at an average age of 54 years (standard deviation $(S D)=16.1$ ), and had a median duration of LBP of 12 months (interquartile range $(I Q R)=6$ to 36$)$. The estimated prevalence of each source of LBP in this population is summarized in Table 1.

Patient characteristics and reports of the presence of hip girdle pain, leg pain, and thigh pain each are summarized for the four diagnostic groups in Table 2. The mean age was significantly different among the source groups $(F(3,153)=27.5, P<0.001)$. IDD cases were significantly younger than FJP, SIJP, and Other source groups and FJA was significantly younger than Other sources; mean age was not significantly different between FJA and SIJ or between SIJ and Other sources. The percentage of patients reporting hip girdle pain was not significantly different among the source groups (chi-square $=5.5, \mathrm{df}=3, \mathrm{p}=0.14$ ). The Other source group had very low frequency counts of reports of either leg pain $(n=1)$ or thigh pain $(n=0)$ and the sample size assumption is not met for chi-square test. The Other group was excluded from the analysis of leg pain and thigh pain. Looking at only the IDD, FJP, and SIJP groups, the percentage of patients reporting either leg pain (chi-square $=0.48, \mathrm{df}=2, P=0.79$ ) or thigh pain (chi-square $=2.0, \mathrm{df}=2, P=0.37$ ) was not significantly different among the source groups.

Table 1. Prevalence of Source of Chronic Low Back Pain

\begin{tabular}{|l|c|c|c|}
\hline & Count & Prevalence & 95\% CI \\
\hline Intervertebral Disc (IDD) & 68 & 43.3 & $(35.8,51.1)$ \\
\hline Lumbar Facet Joint(s) (FJA) & 49 & 31.2 & $(24.5,38.8)$ \\
\hline Sacroiliac Joint(s) (SIJ) & 28 & 17.8 & $(12.6,24.6)$ \\
\hline Other & 12 & 7.6 & $(4.4,12.9)$ \\
\hline Pelvic Insufficiency Fracture & 2 & 1.3 & $(0.4,4.5)$ \\
\hline Vertebral Insufficiency Fracture & 4 & 2.5 & $(1.0,6.4)$ \\
\hline Baastrup's Disease & 2 & 1.3 & $(0.4,4.5)$ \\
\hline Fusion Hardware Mediated Soft Tissue Pain & 4 & 2.5 & $(1.0,6.4)$ \\
\hline
\end{tabular}


Table 2. Patient Characteristic by Source of Chronic Low Back Pain

\begin{tabular}{|l|c|c|c|c|c|}
\hline & Overall & IDD & FJA & SIJ & Other \\
\hline Female, count (percent) & $103(65.6)$ & $38(55.9)$ & $34(69.4)$ & $25(89.3)$ & $6(50.0)$ \\
\hline Duration (months), median (IQR) & $12(6$ to 36$)$ & $12(6$ to 33$)$ & $17(7$ to 36$)$ & $12(3$ to 60$)$ & $10.5(2$ to 33$)$ \\
\hline Age (years), mean (SD) & $54.1(16.1)$ & $43.7(10.4)$ & $59.8(12.8)$ & $62.3(17.5)$ & $70.8(16.4)$ \\
\hline Hip/Girdle Pain, count (percent) & $70(44.5)$ & $29(42.6)$ & $25(51.0)$ & $14(50.0)$ & $2(16.7)$ \\
\hline Leg Pain, count (percent) & $35(21.38)$ & $15(22.6)$ & $13(27.1)$ & $6(21.4)$ & $1(8.3)$ \\
\hline Thigh Pain, count (percent) & $68(43.9)$ & $36(53.9)$ & $21(42.9)$ & $11(39.3)$ & $0(0.0)$ \\
\hline
\end{tabular}

A multivariable generalized logistic regression model was fit to model the probability of the sources of CLBP, excluding the Other source group, with all four predictor variables. Age was significantly associated with source of CLBP $(P<0.001)$, after controlling for hip girdle pain, leg pain, and thigh pain; however none of the other predictor variables were significantly associated with source of CLBP after controlling for the effects of age and each other (hip girdle pain $P=0.42$, leg pain $P=0.56$, thigh pain $P=0.74$ ). There was no evidence of significant pairwise interaction effects between age and hip girdle pain $(P=0.10)$, age and leg pain $(P=0.37)$, hip girdle pain and leg pain $(P=0.38)$, hip girdle pain and thigh pain $(P=0.20)$, or between leg pain and thigh pain $(P=0.99)$. There was however a significant interaction between age and thigh pain ( $P$ $=0.027$ ).

A final multivariable model was fit that included just the significant effects of age, thigh pain, and the age by thigh pain interaction effect. The overall model was significant (chi-square $=62.4, \mathrm{df}=6, P<0.001$ ) and the effects for age $(P<0.001)$, thigh pain $(P=0.026)$, and the age by thigh pain interaction effect $(P=0.021)$ all remained statistically significant. The significant interaction indicates that the effect of age on the source of CLBP depends on thigh pain, and similarly, that the effect of thigh pain on the source of CLBP depends on age. The interaction effect is best illustrated by the plots in Fig. 1. Estimated odds ratios and 95\% confidence intervals comparing the odds of IDD vs. FJP, SIJP vs. IDD, and SIJP vs. FJP between groups of patients with and without thigh pain for a variety of different ages are summarized in the top half of Table 3 . This describes the effect of the presence of thigh pain on source of CLBP for different ages. The bottom half of Table 3 summarizes the estimated odds ratios and $95 \%$ confidence intervals comparing the odds of IDD vs. FJP, SIJP vs. IDD, and SIJP vs. FJP for a group of patients at one age and another group 5 years younger (i.e. a 5 -year increase in age) for those with and without thigh pain. This describes the "effect" of increasing age on the source of chronic LBP.

From the figure we see that the probability of IDD as the source of chronic LBP decreases with age, regardless of the presence or absence of thigh pain. For those with thigh pain, as age increases by 5 years, the odds of IDD vs. FJP decrease significantly by a multiple of $0.470(95 \% \mathrm{Cl}=0.329,0.671)$ and the odds of IDD vs. SIJP decrease significantly by a multiple of $1 / 1.640=$ $0.610(95 \% \mathrm{Cl}=0.431,0.863)$. For those without thigh pain, as age increases by 5 years, the odds of IDD vs. FJP decrease significantly by a multiple of 0.693 (95\% $\mathrm{Cl}=0.545,0.881)$ and the odds of IDD vs. SIJP decrease significantly by a multiple of $1 / 1.888=0.530(95 \% \mathrm{Cl}=$ 0.391, 0.717).

For patients with thigh pain, the probability of FJP increases with age. As age increases by 5 years, the odds of FJP vs. IDD increase significantly by a multiple of $1 / 0.470=2.129(95 \% \mathrm{Cl}=1.491,3.041)$ and the odds of FJP vs. SIJP increase nominally by a multiple of $1 / 0.770$ $=1.298(95 \% \mathrm{Cl}=0.955,1.763)$. The probability of SIJP increases with age until about age 55 then decreases with age for patients with thigh pain. More specifically, as age increases by 5 years, the odds of SIJP vs. IDD increase significantly by a multiple of $1.640(95 \% \mathrm{Cl}=$ $1.159,2.322)$ and the odds of SIJP vs. FJP decrease nominally by a multiple of $0.770(95 \% \mathrm{Cl}=0.567,1.047)$.

For patients without thigh pain, the probability of SIJP increases with age. As age increases by 5 years, the odds of SIJP vs. IDD increase significantly by a multiple of $1.888(95 \% \mathrm{Cl}=1.394,2.556)$ and the odds of SIJP vs. FJP increase significantly by a multiple of $1.308(95 \% \mathrm{Cl}$ $=1.027,1.668)$. The probability of FJP increases with age until about age 65 then decreases with age for patients with thigh pain. More specifically, as age increases by 5 years, the odds of FJP vs. IDD increase significantly by a 


\section{Thigh Pain Present}

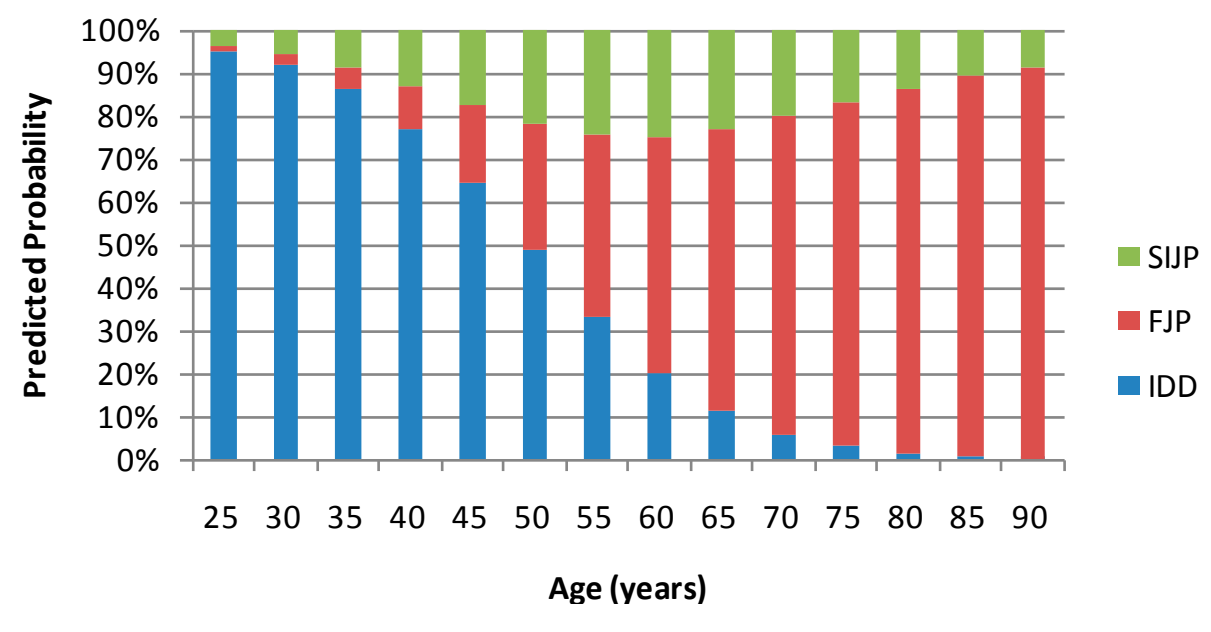

\section{Thigh Pain Absent}

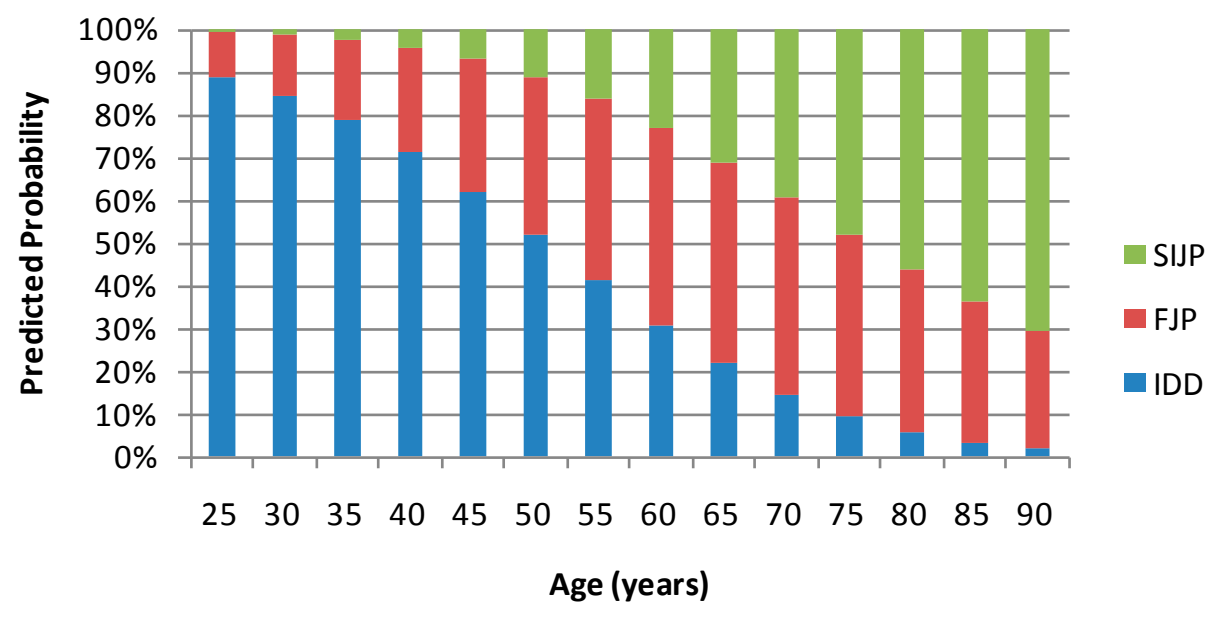

Fig. 1. Age versus source of chronic low back pain by presence/absence of thigh pain

multiple of $1 / 0.693=1.443(95 \% \mathrm{Cl}=1.135,1.834)$ and the odds of FJP vs. SIJP decrease significantly by a multiple of $1 / 1.308=0.764(95 \% \mathrm{Cl}=0.600,0.974)$.

Finally, when comparing patients with and without thigh pain at various ages, the presence/absence of thigh pain only significantly discriminated SIJP from FJP for younger ( 25 - 40 years) patients and older patients (75 - 90 years) with SIJP more likely for younger patients with thigh pain and FJP more likely for older patients with thigh pain.

\section{Discussion}

This retrospective review of CLBP patients demonstrates that the pain referral pattern reported by the patient can be an indicator of the structural source of CLBP. Age correlates with the source of CLBP. Specifically, IDD cases were found to be significantly younger (43.7 years) than cases of FJP (59.8), SIJP (62.3), and Other (70.8) source groups, and FJP cases were significantly younger than Other sources. These findings are congruent with previously reported figures in studies 
Table 3. Adjusted Odds Ratios

\begin{tabular}{|c|c|c|c|c|c|c|c|c|c|c|}
\hline \multirow[b]{2}{*}{ Age } & \multirow[b]{2}{*}{ Thigh Pain } & \multicolumn{2}{|c|}{ IDD vs. FJP } & & \multicolumn{2}{|c|}{ SIJP vs. IDD } & & \multicolumn{2}{|c|}{ SIJP vs. FJP } & \\
\hline & & $\overline{\text { OR }}$ & $95 \%$ CI & & $\overline{\text { OR }}$ & $95 \%$ CI & & OR & $95 \%$ CI & \\
\hline 25 & Present vs. Absent & 8.486 & $(0.754,95.455)$ & & 4.288 & $(0.259,70.974)$ & & 36.385 & $(2.063,641.770)$ & $\dagger$ \\
\hline 30 & & 5.751 & $(0.755,43.821)$ & & 3.726 & $(0.339,40.928)$ & & 21.424 & $(1.740,263.760)$ & $\dagger$ \\
\hline 35 & & 3.897 & $(0.740,20.521)$ & & 3.237 & $(0.434,24.132)$ & & 12.615 & $(1.452,109.585)$ & $\dagger$ \\
\hline 40 & & 2.641 & $(0.700,9.968)$ & & 2.812 & $(0.535,14.779)$ & & 7.428 & $(1.191,46.313)$ & $\dagger$ \\
\hline 45 & & 1.790 & $(0.616,5.200)$ & & 2.444 & $(0.617,9.679)$ & & 4.374 & $(0.950,20.134)$ & \\
\hline 50 & & 1.213 & $(0.475,3.100)$ & & 2.123 & $(0.634,7.113)$ & & 2.575 & $(0.722,9.189)$ & \\
\hline 55 & & 0.822 & $(0.304,2.226)$ & & 1.845 & $(0.552,6.159)$ & & 1.516 & $(0.505,4.556)$ & \\
\hline 60 & & 0.557 & $(0.166,1.875)$ & & 1.603 & $(0.408,6.292)$ & & 0.893 & $(0.312,2.558)$ & \\
\hline 65 & & 0.378 & $(0.082,1.733)$ & & 1.393 & $(0.268,7.228)$ & & 0.526 & $(0.167,1.652)$ & \\
\hline 70 & & 0.256 & $(0.039,1.680)$ & & 1.210 & $(0.165,8.893)$ & & 0.310 & $(0.080,1.193)$ & \\
\hline 75 & & 0.173 & $(0.018,1.670)$ & & 1.051 & $(0.097,11.373)$ & & 0.182 & $(0.036,0.923)$ & $\dagger$ \\
\hline 80 & & 0.118 & $(0.008,1.683)$ & & 0.913 & $(0.056,14.879)$ & & 0.107 & $(0.015,0.745)$ & $\dagger$ \\
\hline 85 & & 0.080 & $(0.004,1.712)$ & & 0.794 & $(0.032,19.740)$ & & 0.063 & $(0.006,0.615)$ & $\dagger$ \\
\hline 90 & & 0.054 & $(0.002,1.751)$ & & 0.689 & $(0.018,26.429)$ & & 0.037 & $(0.003,0.515)$ & $\dagger$ \\
\hline Age & Thigh Pain & OR & $95 \%$ CI & & $\mathbf{O R}$ & $95 \%$ CI & & OR & $95 \%$ CI & \\
\hline \multirow[t]{2}{*}{$\begin{array}{l}5 \text { year } \\
\text { increase }\end{array}$} & Present & 0.470 & $(0.329,0.671)$ & $\dagger$ & 1.640 & $(1.159,2.322)$ & $\dagger$ & 0.770 & $(0.567,1.047)$ & \\
\hline & Absent & 0.693 & $(0.545,0.881)$ & $\dagger$ & 1.888 & $(1.394,2.556)$ & $\dagger$ & 1.308 & $(1.027,1.668)$ & \\
\hline
\end{tabular}

$\mathrm{OR}=$ odds ratio; $\mathrm{CI}=$ confidence interval; $\uparrow$ Statistically significant $(\alpha=0.05)$

assessing age-related prevalence of source of chronic low back pain $(2,29,30)$.

Our multivariable model established that for patients presenting with or without thigh pain, the probability of IDD as the source of chronic low back pain decreases as age increases. Conversely, older age is associated with a higher likelihood of facetogenic or sacroiliac mediated CLBP (2). IDD remains the most prevalent source of chronic low back pain in the young adult population, regardless of the presence or absence of thigh pain. Although age is a powerful predictor of etiology of CLBP, it has less clinical predictive value when used solely to distinguish between facetogenic and sacroiliac mediated pain. Our results demonstrate that pain referral patterns, coupled with age, can assist in differentiating between facet joint and sacroiliac joint structures as the primary source for CLBP. Specifically, a significant interaction was found between age and the presence or absence of thigh pain. As age increases, the odds of SIJP vs IDD and SIJP vS FJP increase significantly in patients without thigh pain. The probability of SIJP was found to increase with age until about age 55 then decrease with age for pts with thigh pain. As age in- creased by 5 years, the odds of SIJP vs IDD increased significantly and the odds of SIJP vs FJP decreased nominally. The presence or absence of thigh pain significantly discriminates SIJP from FJP for younger (25-40) patients and older (75-90) patients with SIJP more likely for younger patients and FJP more likely for older patients. Essentially, younger patients are more likely to suffer from chronic low back pain of discogenic origin, whether or not thigh pain is present as a clinical feature. Older individuals with thigh pain are more likely to suffer from FJP than SIJP up to age 65, and older individuals without thigh pain are more likely to suffer from SIJP than FJP up to age 65.

Each patient reviewed in this protocol did not undergo all diagnostic interventions (discography and diagnostic blocks). Ultimately, one could argue that an erroneous calculation of the prevalence estimate for lumbar IDD, FJP, and SIJP was committed. By not performing discography on every patient, it is plausible that we failed to detect all cases of IDD and have under-reported it. A similar comment could be made about diagnostic FJ and SIJ blocks. However, each patient reviewed underwent definitive diagnostic proce- 
dures until confirmation of the source of that patient's LBP. If a patient was initially evaluated with diagnostic FJ and/or SIJ blocks which were negative, that patient underwent discography to verify the presence of IDD and vice versa.

Opponents of discography and to a lesser degree diagnostic procedures in general, would contend that false positive rates have overestimated our prevalence estimates. Application of meticulous technique and strict adherence to supported operational criteria for discography $(33,36)$ will minimize false positive rates to acceptably low levels (34) allowing accurate detection of clinically meaningful lumbar internal disc disruption $(10,33,36,37)$. Similarly, sufficiently performed diagnostic FJ blocks and SIJ injections are associated with acceptable false positive rates. Lastly, if our findings were skewed by false positives, we would have likely observed different prevalence data less congruent with previous reports. By virtue of the fact that previously reported prevalence data for each diagnostic group (IDD, FJP, SIJP) fall within our Cl's for each group, our findings likely represent an accurate clinical assessment of consecutive LBP patients.

\section{Conclusion}

Our multivariate analysis of the relationship between pain referral patterns and the source of chronic low back pain demonstrates that the presence or absence of thigh pain possesses a significant correlation on the source of chronic low back pain for varying ages, whereas the presence of hip/girdle pain or leg pain did not significantly discriminate between IDD, FJP, or SIJP as the etiology of chronic low back pain. Younger age was predictive of IDD regardless of the presence or absence of thigh pain. These clinical characteristics may aid the clinician in pursuing the most high-yield and cost-effective diagnostic pathway in identifying the source of chronic low back pain.

\section{References}

1. DePalma M, Ketchum J, Queler E, Ruchala M, Powell D, Kouchouch A, Trussell B. What is the etiology of low back pain, and does age effect the prevalence of each etiology? An interim analysis of 170 consecutive cases. Pain Med 2009; 10:949.

2. DePalma MJ, Ketchum JM, Saullo T. What is the source of chronic low back pain and does age play a role? Pain Med 2011; 12:224-233.

3. DePalma MJ, Ketchum JM, Trussell BS, Saullo TR, Slipman CW. Does the location of low back pain predict its source? PM R 2011; 3:33-39.

4. Bernard TN, Kirkaldy-Willis WH. Recognizing specific characteristics of nonspecific low back pain. Clin Orthop Rel Res 1987; 217:266-280.

5. Wurff P, Buijs EJ, Groen GJ. Intensity mapping of pain referral areas in sacroiliac joint pain patients. J Manipulative Physiol Ther 2006; 29:190-195.

6. Fortin JD, Dwyer AP, West S, Pier J. Sacroiliac joint: pain referral maps upon applying a new injection/arthrography technique. Part I: asymptomatic volunteers. Spine 1994; 19:1475-1482.

7. Fortin JD, Aprill CN, Ponthieux B, Pier J. Sacroiliac joint: pain referral maps upon applying a new injection/arthrography technique. Part II: clinical evaluation.
Spine 1994; 19:1483-1489.

8. Slipman CW, Jackson HB, Lipitz JS, Chan KT, Lenrow D, Vresilovic EJ. Sacroiliac joint pain referral zones. Arch Phys Med Rehab 2000; 81:334-338.

9. Fukui S, Nosaka S. Pain patterns originating from the sacroiliac joints. ] Anesth 2002; 16:245-247.

10. Dreyfuss, M. Michaelsen, K. Pauza, J. McLarty and N. Bogduk, The value of medical history and physical examination in diagnosing sacroiliac joint pain. Spine 1996; 21:2594-2602

11. Fortin JD, Vilensky JA, Merkel GJ. Can the sacroiliac joint cause sciatica? Pain Physician 2003; 6:269-271.

12. Jung J, Hyoung K, Shin D, Shin D, Lee J, Kim H, Chung J. Usefulness of pain distribution pattern assessment in decisionmaking for the patients with lumbar zygapophyseal and sacroiliac joint arthropathy. J Korean Med Sci 2007;22:1048-1054.

13. Maigne, A. Aivaliklis and F. Pfefer, Results of sacroiliac joint double block and value of sacroiliac pain provocation tests in 54 patients with low back pain. Spine 1996; 21:1889-1892.

14. Schwarzer AC, Aprill CN, Bogduk N. The sacroiliac joint in chronic low back pain. Spine 1995; 20:31-37.

15. Slipman CW, Sterenfeld EB, Chou LH,
Herzog R, Vresilovic E. The predictive value of provocative sacroiliac joint stress maneuvers in the diagnosis of sacroiliac joint syndrome. Arch Phys Med Rehabil 1998; 79:288-292.

16. Dreyfuss P, Michaelsen M, Pauza K, McLarty J, Bogduk N. The value of medical history and physical examination in diagnosing sacroiliac joint pain. Spine 1996; 21:2594-2602.

17. Dreyfuss P, Dreyer S, Griffin J, Hoffman J, Walsh N. Positive sacroiliac screening tests in asymptomatic adults. Spine 1994; 19:1138-1143.

18. Mooney V, Robertson J. The facet syndrome. Clin Orthop 1976; 115:149-156.

19. Marks R. Distribution of pain provoked from lumbar facet joints and related structures during diagnostic spinal infiltration. Pain 1989; 39:37-40.

20. McCall IW, Park WH, O'Brien JP. Induced pain referral from posterior lumbar elements in normal subjects. Spine 1979; 4:441-446.

21. Fukui S, Ohseto K, Shiotani M, Ohno K, Karasawa $\mathrm{H}$, Naganuma Y. Distribution of referred pain from the lumbar zygapophyseal joints and dorsal rami. Clin J Pain 1997; 13:303-307.

22. Manchikanti L, Singh V. Review of chronic low back pain of facet joint origin. Pain Physician 2002; 5:83-101. 
23. Laslett $\mathrm{M}$, McDonald B, Aprill CN, Tropp H, Oberg B. Clinical predictors of screening lumbar zygapophyseal joint blocks: Development of clinical prediction rules. Spine J 2006; 6:370-379.

24. Revel M, Poiraudeau S, Auleley GR, Payan C, Denke A, Nguyen M, Chevrot A, Fermanian J. Capacity of the clinical picture to characterize low back pain relieved by facet joint anesthesia: Proposed criteria to identify patients with painful facet joints. Spine 1998; 23:19721976.

25. O'Neill CW, Kurgansky ME, Derby R, Ryan DP. Disc stimulation and patterns of referred pain. Spine 2002; 27:27762781.

26. Schwarzer AC, Aprill CN, Derby R, Fortin J, Kine G, Bogduk N. The prevalence and clinical features of internal disc disruption in patients with chronic low back pain. Spine 1995; 20:1878-81.

27. Wolfer LR, Derby R, Lee JE, Lee SH. Systematic review of lumbar provocation discography in asymptomatic subjects with a meta-analysis of false-positive rates. Pain Physician 2008; 11:513-538.

28. Slipman CW, Patel RK, Zhang L, Vresilovic E, Lenrow D, Shin C, Herzog R. Side of symptomatic annular tear and site of low back pain: Is there a correlation? Spine 2001; 26:165-169.

29. Schwarzer A, Wang SC, Bogduk N, McNaught PF, Lauren R. Prevalence and clinical features of lumbar $z$ joint pain: A study in an Australian population w/ chronic low back pain. Ann Rheum Dis 1995; 54:100-106.

30. Manchikanti L, Manchikanti KN, Cash KA, Singh V, Giordano J. Age-related prevalence of facet-joint involvement in chronic neck and low back pain. Pain Physician 2008;11:67-75.

31. Laslett M, Aprill CN, McDonald B, Young SB. Diagnosis of sacroiliac joint pain: Validity of individual provocation tests and composites of tests. Man Ther 2005; 10:207-218.

32. Laslett M, Young SB, Aprill CN, McDonald B. Diagnosing painful sacroiliac joints: A validity study of a McKenzie evaluation and sacroiliac provocation tests. Aust J Physiother 2003; 49:89-97.

33. Lipetz J. Lumbar pain—An algorithmic methodology. In: Slipman CW, Derby R, Simeone FA, Mayer TG, eds. Interventional Spine: An Algorithmic Approach. London: Elsevier; 2007:975-90.

34. Manchikanti L, Singh V, Pampati V, et al.
Evaluation of the relative contributions of various structures in chronic low back pain. Pain Physician 2001; 4:308-316.

35. Fortin JD, Kissling RO, O'Connor BL, Vilensky JA. Sacroiliac joint innervation and pain. Am J Orthop 1999;28(12):68790. Review.

36. van der Wurff P, Buijs EJ, Groen GJ. A multitest regimen of pain provocation tests as an aid to reduce unnecessary minimally invasive sacroiliac joint procedures. Arch Phys Med Rehabil 2006; 87:10-14.

37. Patel RK, Slipman CW. Lumbar spine disorders lumbar degenerative disk disease. eMedicine Specialties Phys Med Rehab 2007.

38. Derby R, Kim BJ, Chen Y, Seo KS, Lee $\mathrm{SH}$. The relation between annular disruption on computed tomography scan and pressure-controlled discography. Arch Phys Med Rehabil 2005; 86:15341538.

39. Lumbar disc stimulation (provocation discography). In: Bogduk N, ed. Practice Guidelines. Spinal Diagnostic and Treatment Procedures. San Francisco, CA: International Spinal Intervention Society; 2004. pp. 20-46. 